12,05

\title{
Нанокомпозиты оксид графена/оксид железа (GrO/FeOx) для биомедицины: синтез и исследования
}

\author{
(C) A.C. Камзин ${ }^{1}$, I.M. Obaidat ${ }^{2}$, B.C. Козлов ${ }^{3}$, E.B. Воронина ${ }^{4}$, V. Narayanaswamy ${ }^{5}$, I.A. Al-Omari ${ }^{6}$ \\ ${ }^{1}$ Физико-технический институт им. А.Ф. Иофффе РАН, \\ Санкт-Петербург, Россия \\ ${ }^{2}$ Department of Physics, United Arab Emirates University, \\ Al-Ain 15551, UAE \\ ${ }^{3}$ Петербургский институт ядерной фризики им. Б.П. Константинова, \\ Санкт-Петербург, Россия \\ ${ }^{4}$ Институт физики Казанского федерального университета, \\ Казань, Россия \\ ${ }^{5}$ Department of Geology, United Arab Emirates University, \\ Al-Ain 15551, UAE \\ ${ }^{6}$ Department of Physics, Sultan Qaboos University, \\ P.O. Box 36, Muscat PC 123, Sultanate of Oman \\ E-mail: ASKAM@mail.ioffe.ru
}

Поступила в Редакцию 16 января 2021 г.

В окончательной редакции 16 января 2021 г.

Принята к публикации 21 января 2021 г.

\begin{abstract}
Представлены исследования свойств и структуры магнитных нанокомпозитов оксид графена $\mathrm{GrO} /$ оксид железа $\mathrm{FeOx}$, синтезированных механохимическим методом с различным содержанием компонент в весовых процентах, GrO:FeOx, а именно: 20:80, 50:50 и 80:20. Метод механохимического синтеза представляет собой механический процесс измельчения в шаровой мельнице в водной среде порошка оксида железа вместе с оксидом графена. Синтезированные магнитные нанокомпозиты $\mathrm{GrO} / \mathrm{FeOx}$ исследованы методами рамановской спектроскопии, магнитометра с вибрирующим образцом и мёссбауэровской спектроскопии. Мёссбауэровские исследования позволили определить фазовый состав и структуру синтезированных магнитных нанокомпозитов $\mathrm{GrO} / \mathrm{FeOx}$. Данные мёссбауэровской спектроскопии показали, что композиты $\mathrm{GrO} / \mathrm{FeOx}$ состоят из фазы магнетита $\mathrm{Fe}_{3} \mathrm{O}_{4}$ и магнитных наночастиц в парамагнитном состоянии, что согласуется с данными рентгеноструктурных исследований. По результатам мёссбауэровской спектроскопии установлено, что кроме магнетита в магнитных нанокомпозитах $\mathrm{GrO} / \mathrm{FeOx}$ присутствует гематит $\alpha-\mathrm{Fe}_{2} \mathrm{O}_{3}$, а также фазы, идентифицированные как карбиды железа и обедненные железом кластеры углерода. Последние не были обнаружены методом рентгеновской дифракции, по-видимому, потому, что их количество незначительно и они находятся в аморфном состоянии. Полученные результаты показывают, что графен является не просто источником углерода при помоле в шаровой мельнице, но обладает собственной реакционной способностью и способностью генерировать новые фазы при механохимической активации. На основании проведенных мёссбауэровских исследований получена уникальная и важная информация о магнитной структуре магнитных нанокомпозитов $\mathrm{GrO} / \mathrm{FeOx}$. Результаты исследований позволяют объяснить магнитные свойства магнитных нанокомпозитов $\mathrm{GrO} /$ магнитные частицы, что важно для разработки и синтеза с использованием оксида графена высокоэффективных магнитных нанокомпозитов для различных применений, в том числе, для биомедицины.
\end{abstract}

Ключевые слова: нанокомпозит оксид графена/феррооксид, механохимический метод синтеза, мёссбауэровская спектроскопия.

DOI: 10.21883/FTT.2021.06.50944.004

\section{1. Введение}

Магнитные наночастицы (МНЧ) обладают уникальными свойствами, существенно отличающимися от свойств макроскопических кристаллов, что позволяет использовать МНЧ в различных областях: в литий-ионных батареях, суперконденсаторах, катализе, в качестве сенсоров, накопителей энергии ипр. (см. [1,2] и ссылки там), а также в различных областях биомедицины [3], таких как магнитная гипертермия, целевая доставка ле- карств, контрастирующего вещества в диагностической магнитно-резонансной томографии и др. [3-7].

Магнитные наночастицы оксида железа (FeOx), среди которых магнетит $\left(\mathrm{Fe}_{3} \mathrm{O}_{4}\right)$, обладающий самой низкой токсичностью, привлекают большое внимание из-за широкого спектра их применений в биомедицине $[1,2]$. Однако, слабый магнитный отклик магнетита, а также химическая нестабильность не позволяют расширить возможности его использования (см. [8] и ссылки там). Поэтому разрабатываются технологии модификации по- 
верхности частиц магнетита, например, путем создания композитов в форме ядро/оболочка с контролируемыми размерами ядра и оболочки [8-10].

В связи с этим, необходимы альтернативные агенты с сильной абсорбцией, а также высокой стабильностью. До сих пор агенты на основе углерода, такие как фуллерены, углеродные нанотрубки и графен, рассматриваются как многообещающие альтернативы магнитным наночастицам для биомедицины из-за их отличительных физических и химических свойств. Наличие атомов углерода придает карбидам железа превосходную механическую прочность и химическую инертность, что делает их важными компонентами металлических сплавов и твердых покрытий.

В последние годы большие усилия исследователей направлены на функционализацию поверхности магнитных наночастиц с использованием двумерного кристалла графена (Gr) толщиной в один атом [11]. Интерес к графену вызван его удивительными электрическими, оптическими, термическими и механическими свойствами, делающими Gr перспективным для применений в различных областях $[12,13]$, в том числе и в нано- и биомедицине [14-17]. Использование оксида графена GrO в биомедицине обусловлено уникальной химической структурой, позволяющей иммобилизовать различные материалы [12], включая металлы и флуоресцентные зонды, а также клетки, лекарства, биомолекулы. Однако использование Gr в биомедицине ограничено его токсичностью. Это препятствие устраняется созданием менее токсичных высокостабильных магнитных нанокомпозитов (МНК) Gr/магнетик. В ряде работ была показана перспективность использования оксида графена ( $\mathrm{GrO})$ для создания $\mathrm{MHK} \mathrm{GrO} / \mathrm{FeOx}$ как агентов при магнитной гипертермии для уничтожения клеток злокачественной опухоли $[7,18,19]$, для диагностики в качестве агента, повышающего контрастность снимков магнитной резонансной томографии [20], для локализации и лечения посредством целевой доставки лекарств [21], а также для создания высокочувствительных биосенсоров [22]. Наноструктуры $\mathrm{GrO} /$ магнетик перспективны для тераностики [22] - метода, сочетающего диагностику и лечение опухолей [10]. МНК на основе графена $\mathrm{GrO} / \alpha-\mathrm{Fe}_{2} \mathrm{O}_{3}$ открывает новые возможности лечения глиобластомы [23], одной из наиболее злокачественных и агрессивных $[4,24]$ опухолей головного мозга, лечение которой представляет собой сложнейшую онкологическую задачу.

Для развития применений $\mathrm{MHK} \mathrm{GrO} /$ наномагнетик в биомедицине необходимы высокоэффективные нанокомпозиты на основе графена, что требует не только исследований структуры и свойств МНЧ Gr/наномагнетик, но также изучения взаимодействия компонентов, образующих подобные наноструктуры, их влияния друг на друга и эффектов, возникающие в промежуточном слое между этими компонентами. Поэтому для характеризации МНК $\mathrm{GrO} / \mathrm{FeOx}$ используются различные методики (см. например $[14,15,18,22])$, в том числе мёссбауэровская спектроскопия $[13,25]$, позволяющая получать очень важную информацию о фазовом составе оксида железа, устанавливать наличие и процентное содержание магнетита $\left(\mathrm{Fe}_{3} \mathrm{O}_{4}\right)$, гематита $\left(\alpha-\mathrm{Fe}_{2} \mathrm{O}_{3}\right)$, маггемита $\left(\gamma-\mathrm{Fe}_{2} \mathrm{O}_{3}\right)$, вюстита и других оксидов железа в исследуемом материале $[8,9]$, что недоступно другим методикам.

В настоящей работе представлены результаты исследований МНК $\mathrm{GrO} / \mathrm{FeOx}$, синтезированных методом механохимического помола в шаровой мельнице предварительно подготовленных компонентов: оксидов графена GrO и железа FeOx. Оксид графена был получен предложенным Хаммерсом методом помола в шаровой мельнице [26], модифицированным в [27]. Преимущество такого метода заключается в том, что синтез $\mathrm{GrO}$ происходит без изменения его химической каркасной структуры, а также позволяет получить GrO в больших количествах [28]. Наночастицы оксидов железа могут быть синтезированы различными способами, например, золь-гель-методом, а также использованным нами методом соосаждения [29]. В [18,30] было показано, что использование воды, как среды для размалывания гематита $\left(\alpha-\mathrm{Fe}_{2} \mathrm{O}_{3}\right)$, позволяет получить $\mathrm{Fe}_{3} \mathrm{O}_{4}$ (магнетит), поскольку при сухом размалывании гематита фаза магнетита не образуется. При этом, меняя соотношение компонентов и длительность времени измельчения, можно управлять магнитными свойствами $\mathrm{MHK} \mathrm{GrO} / \mathrm{Fe}_{3} \mathrm{O}_{4}[18]$. Поэтому компоненты $\mathrm{GrO}$ и $\mathrm{FeOx}$ перемешивались в шаровой мельнице в водной среде.

\section{2. Материалы для синтеза и методики измерений}

Графитовый порошок (99.9995\%) и тетрагидрат хлорида железа были предоставлены фирмой Alfa Aesar (Индия). Серная кислота (98\%, AR) и нитрат натрия, метиламин (около 40\% LR) были получены от SDFCL (Индия), а перманганата калий (молекулярная масса $158.034 \mathrm{~g} / \mathrm{mol}, \mathrm{AR})$ — от Thomas Baker. Безводный хлорид железа (LR) был получен от Sisco Research Laboratories Pvt. Ltd. (SRL) (Индия). Все химические вещества для синтеза наночастиц и нанокомпозитов использовались без дополнительной очистки. Рентгеновские дифрактограммы синтезированных образцов были получены с помощью аналитической системы X-Pert PAN с источником излучения $\mathrm{Cu}-K_{\alpha}$. Рамановские спектры были получены для образцов в исходном состоянии с использованием микроскопа (HORIBA Jobin Yvon, Lab RAM HR), состоящего из твердотельного лазеpa с диодной накачкой, работающего на длине волны $532 \mathrm{~nm}$, и детектора с зарядовой связью. Измельчение смеси компонентов для получения нанокомпозита (НК) $\mathrm{GrO} / \mathrm{FeOx}$ проводили с использованием виалы из хромированной стали в планетарной шаровой мельнице (Eloquent Technologies, Индия). Магнитные измерения в постоянном магнитном поле были выполнены с использованием магнетометра с вибрирующим образцом Quantum Design в устройстве для измерения физических свойств. 
Мёссбауэровские спектры (МС) регистрировались с помощью мёссбауэровского спектрометра, работающего в режиме постоянных ускорений с треугольной формой изменения доплеровской скорости движения источника относительно поглотителя. Измерения проводились в геометрии пропускания гамма-квантов через исследуемый образец. Источником $\gamma$-квантов служил изотоп Co-57 в матрице Rh. Калибровка шкалы скоростей проводилась с использованием поглотителя из металлической фольги $\alpha$-Fe. Экспериментальные мёссбауэровские спектры были математически обработаны с помощью программы, использующей метод наименьших квадратов и лоренцевскую форму спектральных линий, а также метод расшифровки спектров восстановлением распределений параметров сверхтонких взаимодействий (СТВ), реализованных в программе SpectrRelax [31]. Величины изомерных сдвигов приведены относительно металлической фольги $\alpha$-Fe при комнатной температуре.

\section{3. Синтез компонентов $\mathrm{GrO}$ и $\mathrm{FeOx}$ для нанокомпозитов $\mathrm{GrO} / \mathrm{FeOx}$}

\section{1. Синтез оксида графена (GrO)}

Оксид графена синтезировали методом Хаммерса [26] с небольшими модификациями [27]. В стакан с $2 \mathrm{~g}$ графитового порошка и $1 \mathrm{~g} \mathrm{NaNO}_{3}$ добавляли $50 \mathrm{~mL}$ концентрированной кислоты $\mathrm{H}_{2} \mathrm{SO}_{4}$. Полученная смесь охлаждалась при непрерывном перемешивании до температуры ниже $5^{\circ} \mathrm{C}$ и при этой температуре в смесь постепенно добавлялось $6 \mathrm{~g} \mathrm{KMnO}_{4}$, причем температура при этом поддерживалась менее $15^{\circ} \mathrm{C}$. После добавления $\mathrm{KMnO}_{4}$ смесь нагревалась до $35^{\circ} \mathrm{C}$ и выдерживалась при этой температуре в течение $30 \mathrm{~min}$, затем в смесь разбавлялось $80 \mathrm{~mL}$ дистиллированной воды. При добавлении воды из-за экзотермической реакции температура реакционной смеси повышалась до $80^{\circ} \mathrm{C}$. При этой температуре смесь поддерживалась внешним нагревом в течение $20 \mathrm{~min}$ и затем охлаждалась до комнатной температуры. К полученной смеси постепенно при комнатной температуре добавлялся синтезированный оксид графена - смесь $100 \mathrm{~mL}$ воды и $3 \mathrm{~mL} \mathrm{30 \% -ой} \mathrm{перекиси}$ водорода $\mathrm{H}_{2} \mathrm{O}_{2}$. Супернатант (жидкость над осадком) после осаждения сливался, а оставшийся осадок в виде оксида графена GrO промывался $100 \mathrm{ml}$ воды и $100 \mathrm{ml}$ 30\%-ой соляной кислоты $\mathrm{HCl}$.

\section{2. Синтез наночастиц FeOx и нанокомпозита GrO/FeOx}

Для синтеза $\mathrm{FeOx}$ методом соосаждения расчетное количество солей $\mathrm{FeCl}_{2}$ и $\mathrm{FeCl}_{3}$ растворялось в деионизированной воде. К этому раствору медленно добавляли $\mathrm{NaOH}$ до получения $\mathrm{pH} \approx 12$. Этот раствор нагревался в течение $30 \mathrm{~min}$ до $70^{\circ}$ и затем охлаждался до комнатной температуры. Синтезированный порошок промывался
Таблица 1. Обозначения композитов $\mathrm{GrO} / \mathrm{FeOx}$, полученных из смесей наночастиц $\mathrm{GrO}$ и $\mathrm{FeOx}$ в соответствующих весовых процентах

\begin{tabular}{c|c|c|c}
\hline Образец & $\mathrm{GrO}, \mathrm{wt} \%$ & $\mathrm{HЧ} \mathrm{FeOx,} \mathrm{wt} \%$ & MHK GrOx/FeOx, wt\% \\
\hline $\mathrm{A}$ & 80 & 20 & $80: 20$ \\
$\mathrm{~B}$ & 50 & 50 & $50: 50$ \\
$\mathrm{C}$ & 20 & 80 & $20: 80$
\end{tabular}

деионизированной водой, фильтровался с использованием фильтровальной бумаги Whatman и сушился под инфракрасной лампой. Рентгеновский дифракционный анализ полученного порошка показал, что это наночастицы магнетита $\mathrm{Fe}_{3} \mathrm{O}_{4}$.

Для синтеза нанокомпозитов $\mathrm{GrO} / \mathrm{FeOx}$ смешивались рассчитанные по массам количества наночастиц $\mathrm{GrO}$ и $\mathrm{FeOx}$. Полученная смесь и стальные шарики в соотношении 1:20 по массам, помещались во флакон из хромированной стали, который устанавливался в планетарную шаровую мельницу. Средой для измельчения служила деионизированная вода. В результате были получены составы, представленные в табл. 1, где буквами А, В и $\mathrm{C}$ обозначены МHK $\mathrm{GrO} / \mathrm{FeOx}$ с соответствующим соотношением компонентов.

\section{4. Характеризация нанокомпозитов $\mathrm{GrO} / \mathrm{FeOx}$, результаты и обсуждение}

\section{1. Рентгеновская дифракция}

На рис. 1 представлены рентгеновские дифрактограммы как компонентов, используемых для получения нанокомпозитов, так и МНК $\mathrm{GrO} / \mathrm{FeOx}$. На рентгенограмме наночастиц GrO при угле дифракции 10.7 наблюдается дифракционная линия с большой шириной на полувысоте, соответствующая фазе GrO и указывающая, что расстояние между слоями в $\mathrm{GrO}$ составляет $\sim 0.82 \mathrm{~nm}[32,33]$. На рентгенограммах синтезированных наночастиц $\mathrm{FeOx}$ наблюдаются пики, соответствующие фазе магнетита $\mathrm{Fe}_{3} \mathrm{O}_{4}$ [18,33]. В случае синтезированных MHK $\mathrm{GrO} / \mathrm{FeOx}$ на рентгенограммах наблюдаются только линии фаз $\mathrm{GrO}$ и $\mathrm{Fe}_{3} \mathrm{O}_{4}$. Другие линии, указывающие на наличие в МHK $\mathrm{GrO} / \mathrm{FeOx}$ дополнительных фаз, не присутствуют. Узкие ширины линий означают высокую кристалличность как синтезированных наночастиц $\mathrm{FeOx}$, так и магнитных частиц в МНК GrO/FeOx. Интенсивности спектральных линий, соответствующих фазе $\mathrm{Fe}_{3} \mathrm{O}_{4}$ на рентгенограммах МНК $\mathrm{GrO} / \mathrm{FeOx}$, повышаются с увеличением доли $\mathrm{HЧ} \mathrm{FeOx} \mathrm{в}$ МНК. В случае МНК $\mathrm{GrO} / \mathrm{FeOx}$ линия при $2 \theta=10.3100$, соответствующая плоскости (001) в $\mathrm{GrO}$, не наблюдается. Это связано как с тем, что присутствие НЧ предотвращает агрегацию, так и с тем, что выравнивания слоев $\mathrm{GrO}$ при высыхании капли не происходит. Полуширина пика максимальной интенсивности (311) 


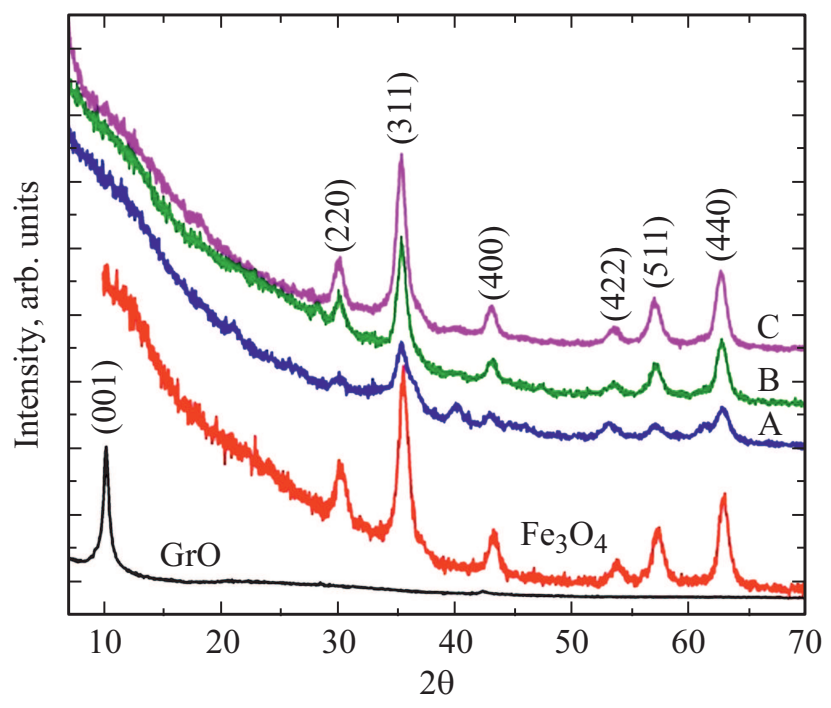

Рис. 1. Рентгеновские дифрактограммы $\mathrm{GrOx}$ и $\mathrm{FeOx}$, a также композитов $\mathrm{GrO} / \mathrm{FeOx}$ составов А $(80: 20)$, В $(50: 50)$ и С $(20: 80)$.

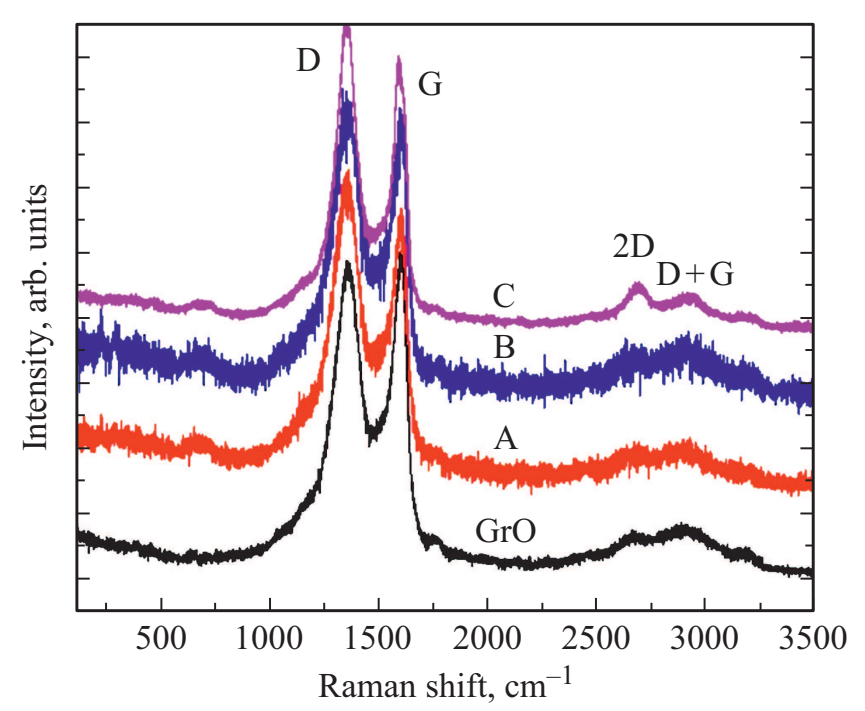

Рис. 2. Рамановские спектры, полученные для наночастиц $\mathrm{GrO}$ и нанокомпозитов $\mathrm{GrO} / \mathrm{FeOx}$ составов $\mathrm{A}(80: 20), \mathrm{B}(50: 50)$ и C $(20: 80)$.

при $2 \theta=35.63$ была использована для расчета средних размеров $\mathrm{HЧ} \mathrm{Fe}_{3} \mathrm{O}_{4}$ и $\mathrm{MHK} \mathrm{GrO} / \mathrm{FeOx}$ по формуле Шеррера [34]. Расчеты показали, что средний размер наночастиц $\mathrm{Fe}_{3} \mathrm{O}_{4}$ составляет $9 \mathrm{~nm}$. Средний размер нанокомпозитов $\mathrm{GrO} / \mathrm{FeOx}$ меняется при измельчении и составляет 8, 9 и $9 \mathrm{~nm}$ для МНК, обозначенных А, В и С соответственно.

\section{2. Рамановская спектроскопия}

Характеризация синтезированных НЧ GrO и МНК $\mathrm{GrO} / \mathrm{FeOx}$ проводилась также с помощью спектроскопии комбинационного рассеяния. Полученные рамановские спектры нанокомпозита $\mathrm{GrO} / \mathrm{FeOx}$ и $\mathrm{HЧ} \mathrm{GrO} \mathrm{показаны}$ на рис. 2, на котором видны два четких пика с полосами D и G на частотах примерно 1353 и $1590 \mathrm{~cm}^{-1}$ соответственно. Положения этих пиков и соотношение интенсивностей аналогичны приведенным для $\mathrm{GrO}$ в $[18,35]$. Полоса $G$ представляет собой рассеяние в режиме E2g, а полоса D - структурный дефект, вызванный окислением слоя графена [35]. В случае свежеприготовленного GrO соотношение интенсивностей линий, принадлежащих полосам D и G, составляет 0.97 . Положения пиков, принадлежащих GrO в нанокомпозитах $\mathrm{GrO} / \mathrm{FeOx}$, примерно такие же, как для чистого GrO. Процесс измельчения не приводит к изменению положения пиков $\mathrm{GrO}$ для нанокомпозитов $\mathrm{GrOx} / \mathrm{FeOx}$. Отношение интенсивностей пиков $\left(I_{\mathrm{D}} / I_{\mathrm{G}}\right)$ для $\mathrm{GrO}$ составляет 0.98, а для компонента GrO в композите $\mathrm{GrO} / \mathrm{FeOx}$ равно 1.05. Сопоставимые значения величин $I_{\mathrm{D}} / I_{\mathrm{G}}$ показывают, что формирование наночастиц $\mathrm{FeOx}$ в $\mathrm{GrO}$ привело к незначительному увеличению дефектов в каркасе $\mathrm{GrO}$ нанокомпозита $\mathrm{GrO} / \mathrm{FeOx}$.

\section{3. Магнитные измерения}

Зависимости намагниченности от внешнего магнитного поля, полученные для наночастиц $\mathrm{FeOx}$ и нанокомпозитов $\mathrm{GrO} / \mathrm{FeOx}$ при комнатной температуре с помощью магнитометра с вибрирующим образцом в диапазоне магнитных полей $\pm 8 \mathrm{~T}$, показаны на рис. 3. Исследуемые образцы обладают малой остаточной намагниченностью, a именно, для НЧ $\mathrm{FeOx}$ намагниченность насыщения $M_{S}=66.0 \mathrm{emu} / \mathrm{g}$, а намагниченности насыщения композитов $\mathrm{GrO} / \mathrm{FeOx}$ с содержанием $\mathrm{FeOx} 20,50$ и $80 \%$ составляют 60.2, 60.4 и $63.8 \mathrm{emu} / \mathrm{g}$, соответственно. Полученная для НЧ $\mathrm{FeOx}$ величина $M_{S}=66.0 \mathrm{emu} / \mathrm{g}$ сопоставима со значением $67.8 \mathrm{emu} / \mathrm{g}$ для $\mathrm{HЧ} \mathrm{Fe}_{3} \mathrm{O}_{4}$ размером $12 \mathrm{~nm}$; для объемных кристаллов $\mathrm{Fe}_{3} \mathrm{O}_{4}$ величина $M_{S}=92 \mathrm{emu} / \mathrm{g}$, а коэрцитивность $H_{C}=323$ Oе [36].

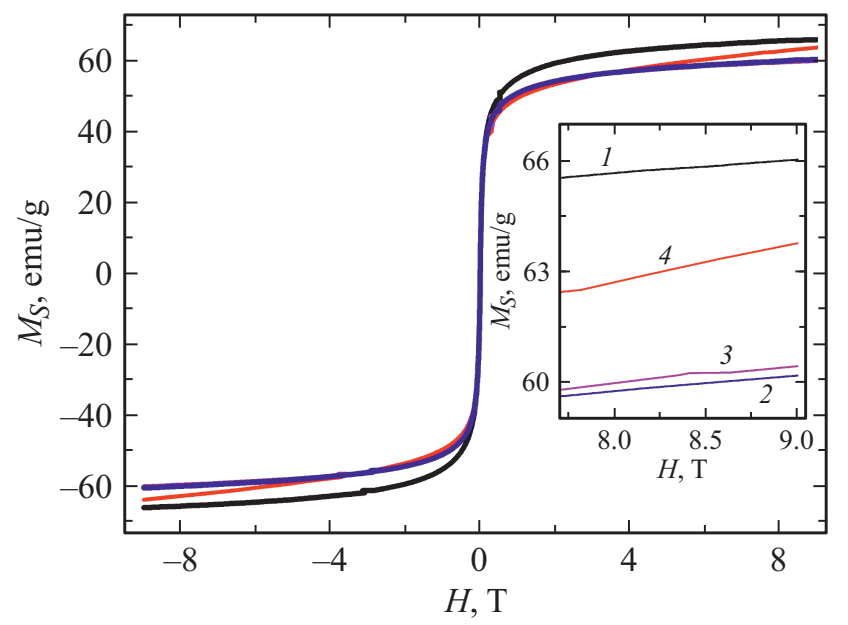

Рис. 3. Зависимости от внешнего магнитного поля $H$ намагниченности $M_{S}$ наночастиц $\mathrm{Fe}_{3} \mathrm{O}_{4}(1)$ и нанокомпозитов GrO/FeOx: 2 - A $(20: 80), 3$ - B (50:50), 4 - C (80:20). 
Малые величины $M_{S}$ и $H_{C}$ по сравнению со значениями для объемных образцов свидетельствуют о суперпарамагнитном состоянии НЧ $\mathrm{FeOx}$ и МНК $\mathrm{GrO} / \mathrm{FeOx}$. Величины $M_{S}$ MHK $\mathrm{GrO} / \mathrm{FeOx}$ меньше значений $M_{S}$ для HЧ FeOx, что связано с понижением намагниченности за счет GrO. Увеличение концентрации частиц $\mathrm{FeOx}$ в составе $\mathrm{MHK} \mathrm{GrO} / \mathrm{FeOx}$ приводит к повышению намагниченности МНК. Низкие значения намагниченности НЧ оксида железа по сравнению с объемными кристаллами обусловлены разупорядочением спиновых моментов, расположенных на поверхности НЧ, либо эффектом скоса спиновых моментов, занимающих положения в поверхностном слое, относительно моментов в объеме частицы. Эти эффекты усиливаются с уменьшением размера наночастиц [37,38].

\section{5. Экспериментальные мёссбауэровские спектры НЧ FeOx и MHK GrO/FeOx и их анализ}

Использование мёссбауэровской спектроскопии обусловлено следующими соображениями. С помощью мёссбауэровской спектроскопии можно определить фазовый состав и установить процентное содержание различных оксидов железа в исследуемом материале, что недоступно другим методикам. Однозначная идентификация частиц гематита, магнетита, маггемита и др. нанометрового размера методом рентгеноструктурного анализа практически невозможна, потому что постоянные кристаллических решеток этих оксидов близки. Уширение линий на дифрактограммах НЧ повышают фактор неопределенности при анализе Ритвельда, и поэтому фактическое процентное содержание магнетита не может быть точно определено. Мессбауэровская спектроскопия позволяет обнаруживать некристаллические (аморфные) оксиды железа, тогда как методом рентгеновской дифракции можно идентифицировать только кристаллические фазы.

MC НЧ FeOx и MHK GrO/FeOx, полученные при комнатной температуре, представлены на рис. 4, экспериментальные значения показаны точками. Модельные спектры, полученные при математической обработке экспериментальных спектров с помощью программы [31], показаны на рис. 4 сплошными линиями. На МС наблюдаются широкие линии зеемановского расщепления, а в области нуля скоростей присутствуют дублеты, указывающие на существование в образцах мелких частиц, находящихся в парамагнитном состоянии.

Первым шагом при анализе экспериментальных МС MHK $\mathrm{GrO} / \mathrm{FeOx}$ было использование модели из двух зеемановских секстиплетов, соответствующих магнетиту $\mathrm{Fe}_{3} \mathrm{O}_{4}$, потому что рентгеноструктурные данные указывали на присутствие в исследуемых МНК $\mathrm{GrO} / \mathrm{FeOx}$ только магнетита: линии поглощения гамма-излучения в области нуля скоростей принадлежат магнитным частицам, находящимся в парамагнитном состоянии. Обработка двумя зеемановскими секстиплетами для $\mathrm{Fe}_{3} \mathrm{O}_{4}$

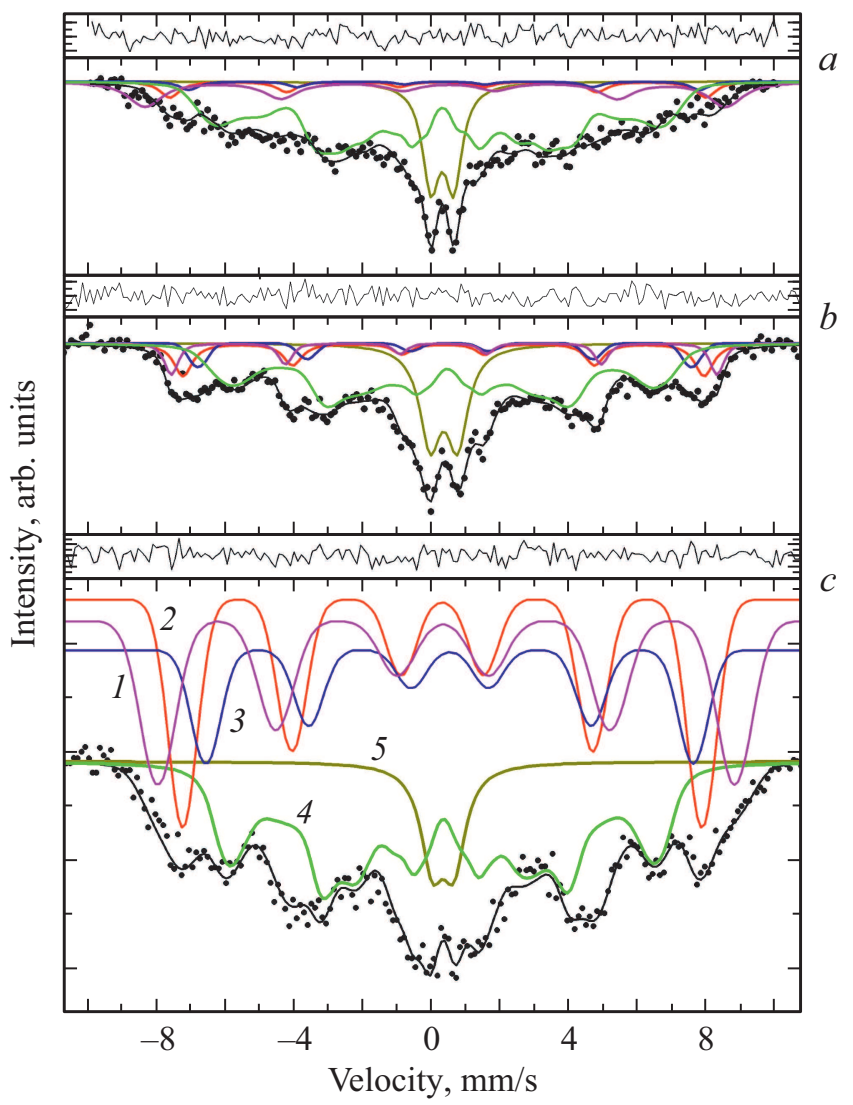

Рис. 4. Экспериментальные мёссбауэровские спектры МНК $\mathrm{GrO} / \mathrm{FeOx}$ при комнатной температуре и их модельное представление: $a-$ спектр МНК $\mathrm{GrO} / \mathrm{FeOx}$ с соотношением компонентов $80: 20, b-50: 50, c-20: 80$. На части с для наглядности обозначены парциальные спектры. Цифрой 1 обозначен парциальный секстиплет, принадлежащий гематиту, 2 и 3 - магнетиту, 4 - секстиплет, полученный восстановлением распределения параметров сверхтонких взаимодействий, 5 - дублет, определяемый частицами парамагнитной фазы.

проводилась по следующим обстоятельствам. Магнетит имеет структуру шпинели, в которой ионы железа занимают два неэквивалентных кристаллографических положения $(A-$ тетраэдрическое и $B-$ октаэдрическое) [39]. Ионы $\mathrm{Fe}^{2+}$ занимают половину позиций октаэдрической $B$-подрешетки, а ионы $\mathrm{Fe}^{3+}$ равномерно распределяются по тетраэдрическим положениям $A$ и оставшейся половине октаэдрических положений $B$. Поэтому на MC магнетита должны присутствовать три зеемановских секстиплета, обусловленные вкладами ионов железа в кристаллографических и позициях $A$ и $B$. Однако, в массивных кристаллах магнетита существует фазовый переход Вервея при $T_{\mathrm{V}}=119 \mathrm{~K}$, сопровождаемый изменением электронного состояния катионов железа в позициях $B$ кристаллической решетки. В области температур выше $T_{\mathrm{V}}$ ионы железа $\mathrm{Fe}^{3+}$ и $\mathrm{Fe}^{2+}$, занимающие позиции $B$, находятся в состоянии электронного обмена и можно говорить о них как о катионах $\mathrm{Fe}^{2.5+}$, которым должен соответствовать один парциальный зе- 
емановский секстиплет (см., например, $[8,13]$ и ссылки там). Следовательно, при комнатной температуре MC магнетита должен состоять из двух зеемановских секстиплетов. Поэтому при математической обработке MC MHK GrO/FeOx была использована модель, состоящая из двух парциальных зеемановских секстиплетов, принадлежащих магнетиту. Однако расчеты показали, что использование такой модели дает существенное отклонение от экспериментальных МС.

Следующим шагом анализа МС было введение в модель расчетов еще одного зеемановского секстиплета, принадлежащего фазе гематита $\left(\alpha-\mathrm{Fe}_{2} \mathrm{O}_{3}\right)$. Основанием для этого были результаты работы [18], в которой было показано, что при синтезе MHK $\mathrm{GrO} / \mathrm{FeOx}$ может формироваться фаза гематита. В гематите ионы кислорода находятся в плотной упаковке, и в октаэдрических пустотах между шестью кислородными анионами находятся катионы трёхвалентного железа. В отличие от магнетита, в гематите ионы железа занимают только одно положение, и МС гематита при комнатной температуре описывается одним секстиплетом. Однако математическая обработка $\mathrm{MC}$ MHK $\mathrm{GrO} / \mathrm{FeOx}$ с использованием модели, учитывающей два секстиплета, идентифицируемых как вклад магнетита, одного секстиплета, принадлежащего гематиту, а также дублета, соответствующего вкладу мелких магнитных НЧ в парамагнитном состоянии, также не привела к удовлетворительному согласию модельных спектров с экспериментальными МС.

Поэтому было сделано предположение, что кроме очень мелких магнитных НЧ в парамагнитном состоянии (вклад в МС от которых наблюдается в виде парамагнитного дублета) и более крупных НЧ в магнитоупорядоченном состоянии (наблюдаемых в МС как зеемановские секстиплеты) в $\mathrm{MHK} \mathrm{GrO} / \mathrm{FeOx}$ могут присутствовать магнитные НЧ, размеры которых распределены между очень мелкими и более крупными НЧ. Кроме того, вклады в мёссбауэровские спектры МНК $\mathrm{GrO} / \mathrm{FeOx}$ могут быть обусловлены разупорядочением спиновых моментов, расположенных на поверхности НЧ, либо эффектом скоса спиновых моментов, занимающих положения в поверхностном слое, относительно моментов в объеме частицы [37,38]. Эти эффекты усиливаются с уменьшением размера наночастиц [37]. Исходя их этих предположений, в модель обработки $\mathrm{MC}$ MHК $\mathrm{GrO} / \mathrm{FeOx}$ был введен четвертый секстиплет. Такой спектр состоит из большого числа парциальных зеемановских секстиплетов, и поэтому был использован метод расшифровки МС, основанный на восстановлении распределения параметров сверхтонкого взаимодействия (СТВ) [31]. Весь диапазон изменения параметров СТВ разбивался на достаточно большое число одинаковых по величине интервалов, каждому из которых соответствовало определенное значение эффективного поля $H_{\text {eff }}$. Каждому значению $H_{\text {eff }}$ соответствовало резонансное поглощение в виде зеемановского секстиплета, форма каждой резонансной линии которого описывалась функцией псевдоВойта

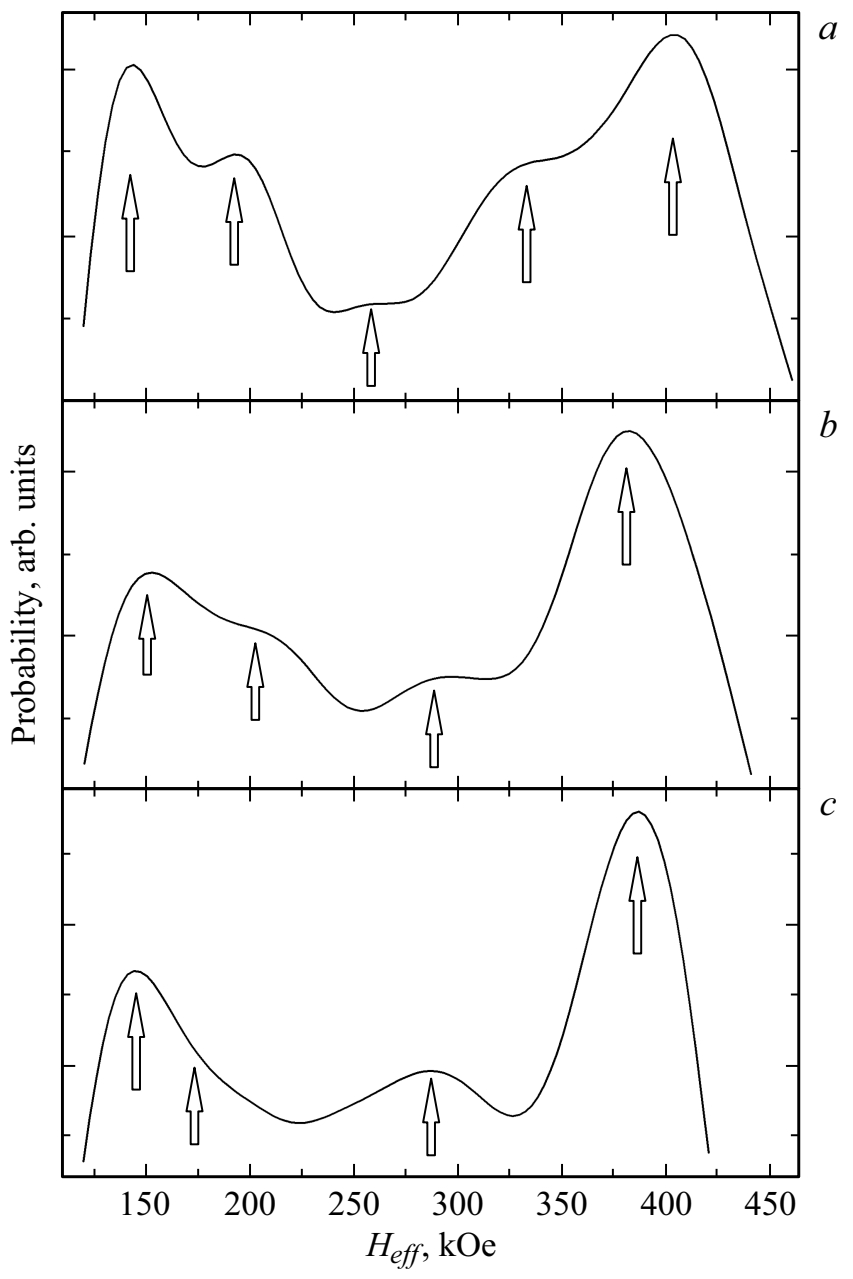

Рис. 5. Результат восстановления функций распределения сверхтонкого магнитного поля $H_{\text {eff }}$ на ядрах ${ }^{57} \mathrm{Fe}$ для МНК $\mathrm{GrO} / \mathrm{FeOx} \mathrm{c} \mathrm{соотношением} \mathrm{компонентов} \mathrm{80:20} \mathrm{-} \mathrm{A,} \mathrm{50:50-}$ В и 20:80 - С. Стрелками указаны максимумы парциальных вкладов, сплошная линия - огибающая для всех использованных в модели Гаусса составляющих.

Таким образом, экспериментальные МС МНК $\mathrm{GrO} / \mathrm{FeOx}$ (рис. 4) были математически обработаны с использованнием модели, состоящей из трех парциальных секстиплетов, относящихся к компонентам оксидов железа (как показано далее, это $\mathrm{Fe}_{3} \mathrm{O}_{4}$ и $\mathrm{Fe}_{2} \mathrm{O}_{3}$ ), дублета и одного секстиплета, полученного методом восстановления распределения параметров СТВ. Такая модель наилучшим образом согласуется с экспериментальными $\mathrm{MC}$ MHK $\mathrm{GrO} / \mathrm{FeOx}$, что подтверждается минимальными величинами разности между модельными и экспериментальными значениями, а также величинами $\chi^{2}$, находящимися в пределах $1.0-1.2$. Распределения эффективных магнитных полей $P\left(H_{e f f}\right)$, полученные из МС $\mathrm{MHY} \mathrm{GrO} / \mathrm{FeOx}$ (рис. 4), представлены на рис. 5.

Для того, чтобы установить принадлежность спектральных линий в МC MHK $\mathrm{GrO} / \mathrm{FeOx}$ отдельным фазам $\left(\alpha-\mathrm{Fe}_{2} \mathrm{O}_{3}\right.$ или $\left.\mathrm{Fe}_{3} \mathrm{O}_{4}\right)$, по положениям линий в $\mathrm{MC}$ были рассчитаны и проанализированы параметры 
Таблица 2. Параметры СТВ, полученные из мёссбауэровских спектров $\mathrm{MHK} \mathrm{GrO} / \mathrm{FeOx}$ при $300 \mathrm{~K}(\delta-$ изомерный сдвиг, $\varepsilon-$ квадрупольное расщепление, $H_{e f f}$ - эффективное магнитное поле, $S$ - площадь линий секстиплета в \% от общей площади спектра); HI - параметры СТВ, восстановленные из секстиплета, обозначенного на рис. 4 цифрой 4.

\begin{tabular}{|c|c|c|c|c|c|}
\hline Образец $\mathrm{GrO} / \mathrm{FeOx}$ & Компонента спектра & $\delta, \mathrm{mm} / \mathrm{s}$ & $\varepsilon, \mathrm{mm} / \mathrm{s}$ & $H_{e f f}, \mathrm{kOe}$ & $S, \%$ \\
\hline \multirow[t]{5}{*}{$\mathrm{A}(80: 20)$} & Дублет & $0.303 \pm 0.014$ & $0.329 \pm 0.013$ & - & $15 \pm 2$ \\
\hline & \multirow{2}{*}{ Секстиплеты $\mathrm{Fe}_{3} \mathrm{O}_{4}$} & $0.250 \pm 0.090$ & $-0.092 \pm 0.080$ & $480 \pm 11$ & $6 \pm 1$ \\
\hline & & $0.380 \pm 0.150$ & $-0.005 \pm 0.042$ & 460 & $3 \pm 2$ \\
\hline & Секстиплет $\alpha$ - $\mathrm{Fe}_{2} \mathrm{O}_{3}$ & $0.350 \pm 0.060$ & $0.047 \pm 0.050$ & 523 & $13 \pm 8$ \\
\hline & $H I$ & $\begin{array}{l}0.280 \pm 0.027 \\
0.271 \div 0.282\end{array}$ & $\begin{array}{c}-0.05 \pm 0.020 \\
-0.040 \div-0.069\end{array}$ & $\begin{array}{l}293 \pm 4.00 \\
120 \div 460\end{array}$ & $64.0 \pm 5.0$ \\
\hline \multirow[t]{5}{*}{$\mathrm{B}(50: 50)$} & Дублет & $0.353 \pm 0.018$ & $0.397 \pm 0.021$ & - & $20 \pm 3$ \\
\hline & \multirow{2}{*}{ Секстиплеты $\mathrm{Fe}_{3} \mathrm{O}_{4}$} & $0.347 \pm 0.040$ & 0 & 470 & $12 \pm 1$ \\
\hline & & $0.457 \pm 0.050$ & $-0.073 \pm 0.050$ & 445 & $6 \pm 4$ \\
\hline & Секстиплет $\alpha$ - $\mathrm{Fe}_{2} \mathrm{O}_{3}$ & $0.351 \pm 0.030$ & $0.010 \pm 0.032$ & $492 \pm 3$ & $8 \pm 6$ \\
\hline & $H I$ & $\begin{array}{l}0.430 \pm 0.040 \\
0.468 \div 0.400\end{array}$ & $\begin{array}{l}-0.04 \pm 0.03 \\
0.019 \div-0.086\end{array}$ & $\begin{array}{l}293 \pm 6.00 \\
120 \div 440\end{array}$ & $55.0 \pm 3.5$ \\
\hline \multirow[t]{5}{*}{$\mathrm{C}(20: 80)$} & Дублет & $0.353 \pm 0.030$ & $0.314 \pm 0.040$ & - & $11 \pm 2$ \\
\hline & \multirow{2}{*}{ Секстиплеты $\mathrm{Fe}_{3} \mathrm{O}_{4}$} & $0.334 \pm 0.031$ & 0 & $468 \pm 1$ & $13 \pm 1$ \\
\hline & & $0.550 \pm 0.080$ & -0.005 & $440 \pm 1$ & $6 \pm 3$ \\
\hline & Секстиплет $\alpha$ - $\mathrm{Fe}_{2} \mathrm{O}_{3}$ & $0.400 \pm 0.050$ & $0.048 \pm 0.040$ & 520 & $11 \pm 7$ \\
\hline & $H I$ & $\begin{array}{l}0.351 \pm 0.027 \\
0.300 \div 0.390\end{array}$ & $\begin{array}{l}-0.043 \pm 0.021 \\
-0.050 \div-0.038\end{array}$ & $\begin{array}{l}289 \pm 4 \\
120 \div 420\end{array}$ & $59 \pm 5.0$ \\
\hline
\end{tabular}

Пр и м е ч н и е. Изомерные сдвиги приведены относительно $\alpha$-Fe.

СТВ, а именно, изомерный сдвиг $\delta$, квадрупольное расщепление $\varepsilon$ и эффективное магнитное поле $H_{e f f}$, представленные в табл. 2. В табл. 2 указаны также фазы, установленные из анализа параметров СТВ. По относительным интенсивностям линий секстиплетов и дублета в МС МНК было определено относительное относительное количество вещества, находящегося в различных фазах, присутствующих в МHК $\mathrm{GrO} / \mathrm{FeOx}$.

Для макрокристаллов $\mathrm{Fe}_{3} \mathrm{O}_{4}$ параметры СТВ при комнатной температуре составляют: для положений $A$ ионов железа $\delta=0.29(1) \mathrm{mm} / \mathrm{s}, H_{e f f}=484(2) \mathrm{kOe}$, для положений $B \delta=0.61(1) \mathrm{mm} / \mathrm{s}, H_{e f f}=455(2) \mathrm{kOe}[13]$. Значения полученных для МНК $\mathrm{GrO} / \mathrm{FeOx}$ величин $\delta$ и $H_{\text {eff }}$ (табл. 2) отличаются от значений для НЧ $\alpha-\mathrm{Fe}_{2} \mathrm{O}_{3}$ и $\mathrm{Fe}_{3} \mathrm{O}_{4}$, которые имеют размеры от 10 до $20 \mathrm{~nm}$ (см. $[8,13,40-43]$ и ссылки там). Это можно объяснить тем, что размеры исследуемых $\mathrm{MHK} \mathrm{GrO} / \mathrm{FeOx}$ меньше $(\sim 9 \mathrm{~nm})$. Соотношение площадей тетраэдрической и октаэдрической магнитных подрешеток для магнетита близко к 1:2 (табл. 2), что указывает на высокую степень стехиометрии магнетита в синтезированном МНК $\mathrm{GrO} / \mathrm{FeOx}$

Восстановленные из MC MHK GrO/FeOx при $300 \mathrm{~K}$ (рис. 4) функции распределения $P\left(H_{e f f}\right)$ показаны на рис. 5. Стрелками на рис. 5 показаны максимумы парциальных вкладов в зависимости вероятностей рас- пределения эффективных полей $P\left(H_{e f f}\right)$ в интервале $0 \leq H_{e f f} \leq 460 \mathrm{kOe}$. Сплошными линиями обозначены огибающие для всех учтенных составляющих спектра, которые считались распределенными по Гауссу. Анализ структуры распределений $P\left(H_{e f f}\right)$, представленных на рис. 5 , показывает, что изменения проявляются в формировании набора парциальных мёссбауэровских спектров со значениями сверхтонких полей $H_{e f f}$, меньшими по сравнению с полями для гематита и магнетита. Для MHK GrO/FeOx с соотношением компонент 80:20 наблюдаются максимумы в области 140, 205, 260, 325 и $405 \mathrm{kOe}$.

Для объяснения механизма формирования максимумов в областях $\sim 405$ и $325 \mathrm{kOe}$ на распределении $P\left(H_{e f f}\right)$ (рис. 5,a) использованы результаты расчетов методом молекулярных орбиталей [44], в которых было показано, что вклады в $H_{e f f}$ от каждой из косвенных обменных связей для иона $\mathrm{Fe}^{3+}$ в структуре шпинели в октаэдрическом и тетраэдрическом положениях составляют 8 и $12 \mathrm{kOe}$, соответственно. Поскольку для иона $\mathrm{Fe}^{3+}$ в положении $A$ в ближайшем катионном окружении находятся 12 ионов железа, принадлежащих $B$-подрешетке, а для $B$-ионов железа -6 ионов железа в положениях $A$, отсутствие половины связей должно привести к понижению эффективных магнитных полей на несколько десятков $\mathrm{kOe}$, что согласуется с данными 
работ $[8,44,45]$. Отсутствие у расположенных на поверхности ионов Fe соседних ионов железа также приводит к понижению $H_{e f f}$ и фрустрации спиновых магнитных моментов ионов, расположенных в следующем от поверхности слое, но без эффектов суперпарамагнетизма, аналогично наблюдаемому в [37] (см. также ссылки в [37]). Повышение в композите количества магнитной компоненты $\mathrm{FeOx} \mathrm{приводит} \mathrm{к} \mathrm{тому,} \mathrm{что} \mathrm{особенности,} \mathrm{на-}$ блюдаемые на кривой $P\left(H_{e f f}\right)$ в области 325 и $405 \mathrm{kOe}$, сливаются и формируют максимум при $390 \mathrm{kOe}$. Возможно, увеличение количества магнитной фазы приводит к преобладанию фазы гематита (что допустимо в пределах ошибки расчетов), в которой ионы железа занимают одно кристаллографическое положение, и максимум на кривой $P\left(H_{e f f}\right)$ в области $390 \mathrm{kOе}$ оносится к ионам $\mathrm{Fe}$, расположенным в поверхностном слое частиц гематита.

Объяснение максимумов, наблюдаемых при 140, 205 и $260 \mathrm{kOe}$ (рис. 5) на основании только свойств оксидов железа невозможно. Поэтому были рассмотрены возможные взаимодействия компонентов, присутствующих в $\mathrm{MHK} \mathrm{GrO} / \mathrm{FeOx}$, а именно, ионов углерода с оксидами железа. В ряде работ было установлено, что ионы углерода в графите или в оксиде графена при синтезе композитов взаимодействуют с ионами железа ферооксидов, формируя соединения карбида железа (FехСу) (см. [25,46-58] и ссылки там). Присутстввие мёссбауровских вкладов со значениями полей в интервале $110 \leq H_{\text {eff }} \leq 290 \mathrm{kOe}$ может определяться атомами железа, для которых ближайшие атомы углерода являются изолированными примесями внедрения. При этом образуется когерентная с матрицей карбидная фаза, обладающая ГПУ структурой, для которой характерна одна магнитная позиция атомов железа с эффективными полями в интервале $260 \leq H_{\text {eff }} \leq 290 \mathrm{kOe}$ (см. [48] и ссылки там). При повышении в композите количества $\mathrm{FeOx}$ положение такого максимума на кривой $P\left(H_{e f f}\right)$ сдвигается от 265 до $290 \mathrm{kOe}$ (рис. 5). По-видимому, при этом отношение числа внедряемых атомов углерода к количеству оксида железа уменьшается, что приводит к уменьшению количества углерода, вошедшего в ферроксиды, и повышению $H_{e f f}$. Изменения вида кривой $P\left(H_{e f f}\right)$ для МС при увеличении количества оксида железа свидетельствуют о продолжении процесса карбонизации.

Максимумы вблизи 110 и $220 \mathrm{kOe}$ на кривых распределений $P\left(H_{e f f}\right)$ (рис. 5) также относятся к ионам железа, принадлежащим карбидам железа [54-57]. Проведенный в работе [48] анализ параметров СТВ показал, что они могут быть сопоставлены с параметрами для аморфной составляющей карбида железа [58]. Следовательно, можно утверждать, что в исследуемых МНК $\mathrm{GrO} / \mathrm{FeOx}$ присутствующие включения карбидов железа находятся в аморфном состоянии, и их обнаружение методом рентгеноструктурной дифракции невозможно.

Мессбауэровские исследования свойств как гематита, так и магнетита, проведенные после механохимической активации с графитом [49] и графеном [25], показали, что при небольшом времени измельчения атомы углерода проникают в структуру как гематита, так и магнетита, а при больших временах измельчения формируются фазы, идентифицированные как карбиды железа и обедненные железом кластеры углерода. Следует отметить, что полученные при обработке экспериментальных МС компоненты, идентифицированные как вклады магнетита и гематита (рис. 4, $a$ ), аналогичны наблюдаемым в $[25,49]$ мёссбаэуровским спектрам магнетита и гематита с карбидами железа.

Из кривых распределения эффективных полей (рис. 5) следует, что процесс карбонизации при измельчении в водной среде при повышении количества феррооксида происходит следующим образом. Сперва формируются атомные конфигурации типа $\mathrm{Fe}-\mathrm{C}$. Природа появления набора локальных окружений атомов $\mathrm{Fe}$ с полями $125<H_{e f f}<300 \mathrm{kOe}$ в системе $\mathrm{Fe}-\mathrm{C}$ достоверно не установлена. При повышении количества феррооксида в МНК $\mathrm{GrO} / \mathrm{FeOx}$ процесс карбонизации протекает путем перераспределения углерода в окружениях атомов $\mathrm{Fe}$, что подтверждается изменением вида зависимостей $P\left(H_{e f f}\right)$ в области полей $120<H_{e f f}<325 \mathrm{kOe}$. Проявление компоненты с $H_{e f f} \approx 260 \mathrm{kOе}$ и повышение интенсивности этой линии со смешением в область $H_{e f f} \approx 290 \mathrm{kOе}$ может свидетельствовать о том, что процесс аморфизации в условиях механосинтеза в водной среде не является приоритетным, а лишь сопутствует карбонизации Fе. Таким образом, набор мёссбауэровских спектров и расчитанные распределения $P\left(H_{e f f}\right)$, представленные на рис. 5, являются экспериментальным подтверждением того, что при механохимическом синтезе МНК $\mathrm{GrO} / \mathrm{FeOx}$ формируются карбиды железа. Полученные результаты указывают на особенности кинетики процесса карбонизации, т.е. закономерности изменения параметров СТВ ближайшего окружения атомов Fe при изменении соотношения смешиваемых компонентов. Формирование карбидов железа в МНК графит/магнитные частицы зависисит от метода синтеза. Так, например, в композитах $\mathrm{FeOx} /$ улерод типа ядро/оболочка, полученных методом пиролиза, карбиды железа не обнаружены [60].

В ряде работ показано, что НЧ карбида железа обеспечивают потенциальный компромисс между высокой намагниченностью насыщения и стабильностью в биологических средах. Поэтому карбиды железа перспективны для применений в различных областях, включая магнитную гипертермию, магнитно-резонансную томографию и катализ (см. [60-62] и ссылки там). Можно утверждать, что присутствие карбидов железа в $\mathrm{MHK} \mathrm{GrO} / \mathrm{FeOx}$ не ухудшает, а напротив, улучшает характеристики таких МНК для применений в гипертермии [18].

\section{6. Заключение}

Магнитные нанокомпозиты (MHK) GrO/FeOx успешно синтезированы механохимическим способом, а имен- 
но, измельчением в шаровой мельнице в водной среде смеси предварительно подготовленных компонентов: оксида графена $\mathrm{GrO}$ и наночастиц FeOx. Получены и изучены свойства $\mathrm{MHK} \mathrm{GrO} / \mathrm{FeOx}$ с различным весовым содержанием компонентов $\mathrm{GrO}$ и $\mathrm{FeOx}$, а именно: $20: 80$, $50: 50$ и 80:20, соответственно. Исследования МНК $\mathrm{GrO} / \mathrm{FeOx}$ проведены методами дифракции рентгеновских лучей, рамановской спектроскопии, магнитометрии и мёссбауэровской спектроскопии.

Использование мёссбауэровской спектроскопии позволило установить фазы, образующие магнитную составляющую МHK GrO/FeOx. Показано, что магнитный компонент композитов $\mathrm{GrO} / \mathrm{FeOx}$ состоит из фазы магнетита $\left(\mathrm{Fe}_{3} \mathrm{O}_{4}\right)$ и магнитных наночастиц размерами до $4 \mathrm{~nm}$, находящихся в парамагнитном состоянии, что подтверждает данные рентгеноструктурных исследований. Кроме фазы магнетита, как установлено с помощью мёссбауэровской спектроскопии, в МНК присутствует гематит $\left(\alpha-\mathrm{Fe}_{2} \mathrm{O}_{3}\right)$, а также фазы, идентифицированные как карбиды железа и обедненные железом кластеры углерода. Фазы карбидов железа не были обнаружены методом рентгеновской дифракции, по-видимому, потому, что их количество, во-первых, незначительно и, вовторых, они находятся в рентгеноаморфном состоянии. Присутствие карбидов железа повышает эффективность $\mathrm{MHK} \mathrm{GrO} / \mathrm{FeOx}$ в применениях для гипертермического лечения.

Полученные результаты показывают, что графен является не просто источником углерода при помоле в шаровой мельнице, но обладает собственной реакционной способностью и способностью генерировать новые фазы при механохимической активации. Максимумы, наблюдаемые на кривых распределения эффективных полей при 140, 205 и $260 \mathrm{kOe}$ (рис. 5), объясняются тем, что при помоле в шаровой мельнице оксида железа и графена (или графита) формируются конфигурации, не связанные с положениями атомов в ячейках известных в системе $\mathrm{Fe}-\mathrm{C}$ кристаллических фаз.

Таким образом, на основании проведенных мёссбауэровских исследований впервые получена уникальная и важная информация о магнитной структуре МНК $\mathrm{GrO} / \mathrm{FeOx}$. Результаты исследований позволяют объяснить магнитные свойства МНК GrO/магнитные частицы, что важно для разработки магнитных нанокомпозитов с использованием оксида графена для различных применений, в том числе для биомедицины.

\section{Финансирование работы}

I.M. Obaidat и I.A. Al-Omari выражают благодарность за финансовую поддержку Программе углубленных исследований UAEU (UPAR), грант № 31S364.

\section{Конфликт интересов}

Авторы заявляют, что у них нет конфликта интересов.

\section{Список литературы}

[1] Handbook of Nanomaterials for Industrial Applications / Ed. Chaudhery Mustansar Hussain. Elsevier, Amsterdam (2018). $1076 \mathrm{c}$.

[2] N. Ajinkya, X. Yu, P. Kaithal, H. Luo, P. Somani, S. Ramakrishna. Materials 13, 4644 (2020).

[3] V. Socoliuc, D. Peddis, V.I. Petrenko, M.V. Avdeev, D. SusanResiga, T. Szabó, R. Turcu, E. Tombácz, L. Vékás. Magnetochemistry 2, 2 (2019).

[4] N.V.S. Vallabani, S. Singh, A.S. Karakoti. Current Drug Metabolism 20, 457 (2019).

[5] E. Myrovali, N. Maniotis, T. Samaras, M. Angelakeris. Nanoscale Adv. 2, 408 (2020).

[6] A.G. Roca, L. Gutiérrez, H. Gavilána, M.E.F. Brollo, S. Veintemillas-Verdaguer, M. del Puerto Morales. Adv. Drug Delivery Rev. 138, 68 (2019).

[7] I.M. Obaidat, V. Narayanaswamy, S. Alaabed, S. Sambasivam, C.V.V. Muralee Gopi. Magnetochemistry 5, 67 (2019).

[8] А.С. Камзин, I.M. Obaidat, А.А. Валлиулин, В.Г. Семенов, I.A. Al-Omari. ФТТ 62, 1715 (2020); А.С. Камзин, I.M. Obaidat, A.A. Валлиулин, В.Г. Семенов, I.A. Al-Omari. ФTT 62, 1919 (2020).

[9] K. Simeonidis, C. Martinez-Boubeta, D. Serantes, S. Ruta, O. Chubykalo-Fesenko, R. Chantrell, J. Oro-Sole, L. Balcells, A.S. Kamzin, R.A. Nazipov, A. Makridis, M. Angelakeris. ACS Appl. Nano Mater. 3, 4465 (2020).

[10] S. Zhao, X. Yu, Y. Qian, W. Chen, J. Shen. Theranostics 10, 6279 (2020).

[11] K.S. Novoselov, A.K. Geim, S.V. Morozov, D. Jiang, Y. Zhang, S.V. Dubonos, I.V. Grigorieva, A.A. Firsov. Science 306, 666 (2004).

[12] D. Chen, H. Feng, J. Li. Chem. Rev. 112, 6027 (2012).

[13] I.S. Lyubutin, A.O. Baskakov, S.S. Starchikov, K.-Y. Shih, C.-R. Lin, Y.-T. Tseng, S.-S. Yang, Z.-Y. Han, Yu.L. Ogarkova, V.I. Nikolaichik, A.S. Avilov. Mater. Chem. Phys. 219, 411 (2018).

[14] S. Gurunathan, J.-H. Kim. Int. J. Nanomed. 11, 1927 (2016).

[15] P.T. Yin, S. Shah, M. Chhowalla, K.-B. Lee. Chem. Rev. 115, 2483 (2015).

[16] S.M. Mousavi, S.A. Hashemi, Y. Ghasemi, A.M. Amani, A. Babapoor, O. Arjmand. Drug Metabolism Rev. 51, 12 (2019).

[17] B. Thapa, D. Diaz-Diestra, D. Badillo-Diaz, R.K. Sharma, K. Dasari, S. Kumari, M.B. Holcomb, J. Beltran-Huarac, B.R. Weiner, G. Morell. Sci. Rep. 9, 5633 (2019).

[18] V. Narayanaswamy, I.M. Obaidat, A.S. Kamzin, S. Latiyan, S. Jain, H. Kumar, C. Srivastava, S. Alaabed, B. Issa. Int. J. Mol. Sci. 20, 3368 (2019).

[19] E. Peng, E.S.G. Choo, P. Chandrasekharan, C.T. Yang, J. Ding, K.H. Chuang, J.M. Xue. Small 8, 3620 (2012).

[20] H.P. Cong, J.J. He, Y. Lu, S.H. Yu. Small 6, 169 (2010).

[21] X. Yang, X. Zhang, Y. Ma, Y. Huang, Y. Wang, Y. Chen. J. Mater. Chem. 19, 2710 (2009).

[22] F. Li, Y. Huang, K. Huang, J. Lin, P. Huang. Int. J. Molec. Sci. 21, 390 (2020).

[23] S.A. Makharza, G. Cirillo, O. Vittorio, E. Valli, F. Voli, A. Farfalla, M. Curcio, F. Iemma, F.P. Nicoletta, A.A. ElGendy, G.F. Goya, S. Hampel. Pharmaceuticals 19, 76 (2019).

[24] K. Mahmoudi, A. Bouras, D. Bozec, R. Ivkov, C. Hadjipanayis. International J. Hyperthermia 34, 1316 (2018).

[25] M. Sorescu, M. Allwes. MRS Advances 4, 155 (2019). 
[26] W.S. Hummers, R.E. Offeman. J. Am. Chem. Soc. 80, 1339 (1958).

[27] D.C. Marcano, D.V. Kosynkin, J.M. Berlin, A. Sinitskii, Z. Sun, A. Slesarev, L.B. Alemany, W. Lu, J.M. Tour. ACS Nano 4, 4806 (2010).

[28] T.P. Yadav, R.M. Yadav, D.P. Singh. Nanosci. Nanotechnol. 2, 22 (2012)

[29] K. Zhu, Y. Ju, J. Xu, Z. Yang, S. Gao, Y. Hou. Acc. Chem. Res. 51, 404 (2018).

[30] C. Ding, S. Ni, Z. Chen. China Particuology 5, 357 (2007).

[31] M.E. Matsnev, V.S. Rusakov / AIP Conf. Proc. 1489, 178 (2012); M.E. Matsnev, V.S. Rusakov. AIP Conf. Proc. 1622, 40 (2014).

[32] N. Venkatesha, P. Poojar, Y. Qurishi, S. Geethanath, C. Srivastava. J. Appl. Phys. 117, 154702 (2015).

[33] V. Narayanaswamy, H. Kumar, C. Srivastava, S. Alaabed, M. Aslam, A. Mallya, I. Obaidat. Mater. Express 10, 314 (2020).

[34] A.L. Patterson. Phys. Rev. 56, 978 (1939).

[35] A. Kaniyoor, S. Ramaprabhu. AIP Advances 2, 032183 (2012).

[36] R.N. Panda, N.S. Gajbhiye, G. Balaji. J. Alloys Compd. 326, 50 (2001).

[37] S. Mørup, E. Brok, C. Frandsen. J. Nanomaterials ID 720629 (2013).

[38] А.С. Камзин, A. Bingolbali, N. Dogan, Z. Yesil, M. Asilturk. Письма в ЖТФ 45, 19, 51 (2019).

[39] Я. Смит, Х. Вейн. Ферриты. Изд-во ИЛ., М. (1962). 504 с.

[40] E. Murad, J.H. Johnston. Mossbauer spectroscopy applied to inorganic chemistry / Ed. G.J. Long. Plenum Press, N.Y. (1987). V. 2. P. 507-582.

[41] M. Starowicz, P. Starowicz, J. Zukrowski, J. Przewoznik, A. Lemanski, C. Kapusta, J. Banas. J. Nanopart. Res. 13, 7167 (2011).

[42] S.J. Oh, D.C. Cook, H.E. Townsend. Hyperfine Interact. 112, 59 (1998).

[43] V. Chlan, J. Żukrowski, A. Bosak, Z. Kakol, A. Kozłowski, Z. Tarnawski, R. Řezníček, H. Štěpánková, P. Novák, L. Biało, J.M. Honig. Phys. Rev. B 98, 125138 (2018).

[44] F. van der Woude, G.A. Sawatzky. Phys. Rev. B 4, 3159 (1971).

[45] И.Н. Захарова, М.А. Шипилин, В.П. Алексеев, А.М. Шипилин. Письма в ЖТФ 38, 2, 1 (2012).

[46] Р.Л. Аренц, Ю.В. Максимов, И.П. Суздалев, В.К. Имшенник, Ю.Ф. Крупянский. ФММ 36, 277 (1973).

[47] P. Matteazzi, G. Le Caer. J. Amer. Ceram. Soc. 74, 1382 (1991).

[48] В.А. Баринов, В.А. Цурин, В.А. Казанцев, В.Т. Суриков. ФMM 115, 57 (2014).

[49] M. Sorescu, R. Trotta. MRC Advances 1, 221 (2015).

[50] K. Loizou, S. Mourdikoudis, A. Sergides, M.O. Besenhard, C. Sarafidis, K. Higashimine, O. Kalogirou, S. Maenosono, N. Thi, K. Thanh, A. Gavriilidis. ACS Appl. Mater. Interfaces. 12, 28520 (2020).

[51] X.W. Liu, S. Zhao, Y. Meng, Q. Peng, A.K. Dearden, C.F. Huo, Y. Yang, Y.W. Li, X.D. Wen, Sci. Rep. 6, 26184 (2016).

[52] G. Schinteie, V. Kuncser, P. Palade, F. Dumitrache, R. Alexandrescu, I. Morjan, G. Filoti. J. Alloys Comp. 564, 27 (2013).

[53] F. Dumitrache, I. Morjan, C. Fleacaa, R. Birjega, E. Vasile, V. Kuncser, R. Alexandrescu. Appl. Surf. Science 257, 5265 (2011).
[54] H. Khurshid, Y.A. Abdu, E. Devlin, B.A. Issa, G.C. Hadjipanayis. RSC Adv. 10, 28958 (2020).

[55] X.W. Liu, Z. Cao, S. Zhao, R. Gao, Y. Meng, J.X. Zhu, C. Rogers, C.F. Huo, Y. Yang, Y.W. Lim, X.D. Wen. J. Phys. Chem. C 121, 21390 (2017).

[56] С.В. Ломаева. ФММ 104, 403 (2007).

[57] Е.П. Елсуков, Г.А. Дорофеев, В.М. Фомин, Г.Н. Коныгин, А.В. Загайнов, А.Н. Маратканова. ФММ 94, 43 (2002).

[58] E. Bauer-Grosse, G. Le Caër. Phil. Mag. 56, 485 (1987).

[59] I.S. Lyubutin, C.-R. Lin, Y.-T. Tseng, A. Spivakov, A.O. Baskakov, S.S. Starchikov, K.O. Funtov, C.-J. Jhang, Y.-J. Tsai, H.S. Hsu. Mater. Charact. 150, 213 (2019).

[60] J. Yu, F. Chen, W. Gao, Y. Ju, X. Chu, S. Che, F. Sheng, Y. Hou. Nanoscale Horiz. 2, 81 (2017).

[61] A. Bordet, R.F. Landis, Y.W. Lee, G.Y. Tonga, J.M. Asensio, C.H. Li, P.-F. Fazzini, K. Soulantica, V.M. Rotello, B. Chaudret. ACS Nano 13, 2870 (2019).

[62] A. Gangwar, S.S. Varghese, S.S. Meena, C.L. Prajapat, N. Gupta, N.K. Prasad. J. Magn. Magn. Mater. 481, 251 (2019).

Редактор Е.Ю. Флегонтова 